\title{
The Sound Playground
}

\author{
Tara Daniel \\ Perth Institute of Contemporary Arts \\ c/- 51 James St \\ Perth Cultural Centre, WA, 6003 \\ education@pica.org.au
}

\author{
Linsey Pollak \\ 21 Mountain View Rd \\ Bald Knob, QLD, 4552 \\ linsey@spiderweb.com.au
}

\author{
Michelle Williamson \\ 121 Birchwood Ave \\ Woodlands, WA, 6018 \\ michellejanewilliamson@hotmail.com
}

\section{INTRODUCTION}

The Sound Playground is the result of a term long residency project at Kingston Primary School in regional Western Australia. Sound artist Linsey Pollak, visual and animation artist Michelle Williamson, specialist music teacher Salvatore Basile, specialist art teacher Anne Williams, and more than 70 grade 5 and 6 students collaborated on the project, in partnership with the Perth Institute of Contemporary Arts' pilot arts education program Spark_Lab, which builds innovation capacities in young people through meaningful engagement with contemporary arts practices.

\section{VISUALISATION THROUGH DIGITAL ARTS}

Spark_Lab's aims to develop capacities such as leadership, creativity, risk taking and self efficacy in young people. It does this by connecting students and teachers with practicing contemporary artists and embedding their collaborations in the school community. Kingston Primary School's community wanted a Sound Playground for their campus. Spark_Lab facilitates artist-led and student-driven projects rather than simply building capital works, so the residency focussed on the first (design) stage of this ambitious project. Students conceived and designed their own instruments, sounds and interactive panels to activate digital sounds in a playground environment. They then visualised these ideas, concepts and designs through a variety of animation techniques, producing a film to showcase their very own Sound Playground. The skills and techniques taught to students built on their current, relatively limited, technological expertise, and gave their teachers the ability to continue their learning experiences beyond the duration of the residency. The project filled gaps in the arts curriculum and extended students well beyond its current scope.

\subsection{The artists and technology}

Linsey Pollak is a musician, instrument maker, composer, and educator. Linsey has a reputation for making musical instruments from rubber gloves, carrots, watering cans, chairs, brooms and other found objects. This musical inventiveness also encompasses modern digital technology. Currently Linsey uses a midi wind controller to play and loop samples of everything from voices to frogs. His recent musical installation, Squirt uses frog sound samples, triggered when large acrylic frogs are hit with a stream of water. Linsey showcased his body of work and performed his solo show Live \& Loopy for the entire school, triggering a surge of ideas from students, inspired by what they now saw as possible. Linsey undertook intensive workshops with students and teacher Salvatore Basile, utilising the ipad app Thumbjam to teach skills in composition and integrated professional learning into the residency to ensure ongoing learning for the school community.

Michelle Williamson is an animator, painter and digital media artist. She works with $2 \mathrm{~d}$, puppet, silhouette, hand drawn, claymation and life size scale animation as well as green screen technology, and constantly explores new ways of working as an artist. Michelle taught students about the history of animation, also teaching the old techniques of the Phenakistoscope, Praxinoscope and Zoopraxiscope with innovative flair. She worked extensively with students to visually realise their ideas and designs through film, both depicting what the playground might actually look like, as well as imagery the sounds evoked. Michelle also worked closely with teacher Anne Williams to pass on her knowledge and skills to encourage further work in this medium beyond the residency.

\subsection{The Vision}

The students formulated and visually realised their design concepts in film, and now the school community would like to make the Sound Playground a reality. Whilst it is an innovative, entertaining and complete work, the short film also showcases the project for potential sponsors and funding bodies, creatively depicting the students' ideas, in their own visual (and musical) languages. 


\section{REFERENCES}

ACARA (Australian Curriculum, Assessment and Reporting Authority). (2011) The Shape of the Australian Curriculum: The Arts. ACARA, Sydney.

Cunningham, S. (2008) The Arts, and the Innovation Agenda. Workshop: The Arts and the Innovation Agenda, Sydney, 31 March 2008, CHASS (Council for the Humanities, Arts and Social Sciences), Canberra.

Helyer, N. (2003) Prometheus Bound: Art, Science, Creativity and the Imagination. www.sonicobjects.com/index.php/texts/more/prome theus_bound_art_science_creativity_and_the_imag ination/ (retrieved 3/12/12).

Helyer, N. (2005) Some approaches to sound and listening.

www.sonicobjects.com/index.php/texts/more/some approaches_to_sound_and_listening/_(retrieved 3/12/12).

Leadbeater, C. (2009) The Art of With. Original essay for Cornerhouse, Manchester www.charlesleadbeater.net/cms/xstandard/The $\% 20$ Art\%20of\%20With\%20PDF.pdf (retrieved 15/11/12)

Mowson, B. (2002) A thrilling sono-cranial re-wire. RealTime, Issue \#50, pg. 8.

Robson, J. \& Jaaniste, L. (2010) Growing Future Innovators: A new approach to learning programs for young people. CREATEC, Edith Cowan University, Western Australia.

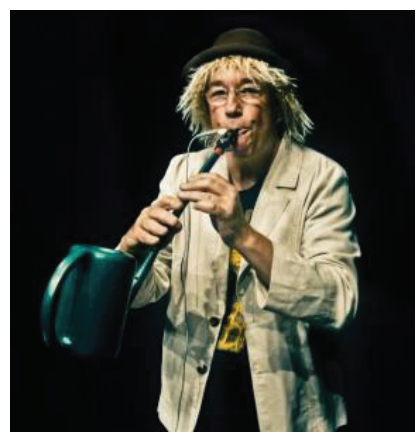

Figure 1: Linsey Pollak plays a watering can in "Live \& Loopy"

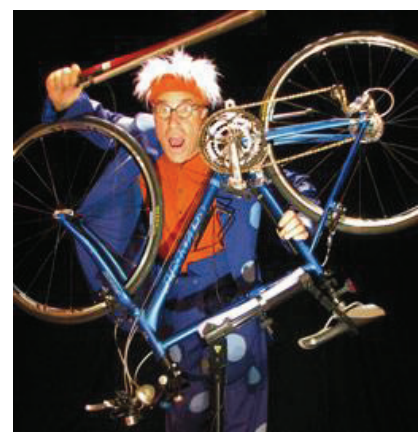

Figure 2: Linsey Pollak plays a bicycle in "Cycology"

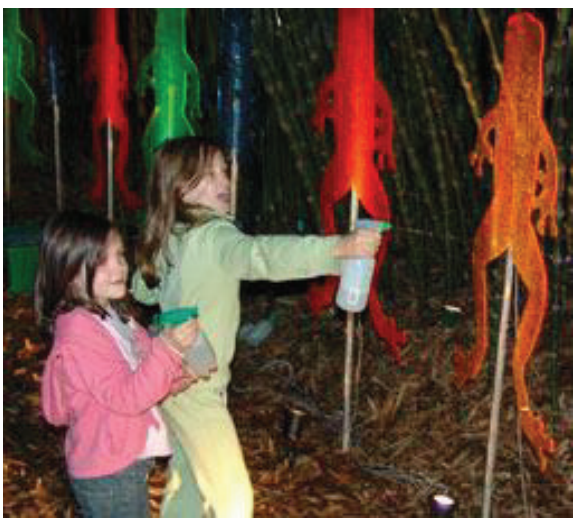

Figure 3: Linsey Pollak's “Squirt”

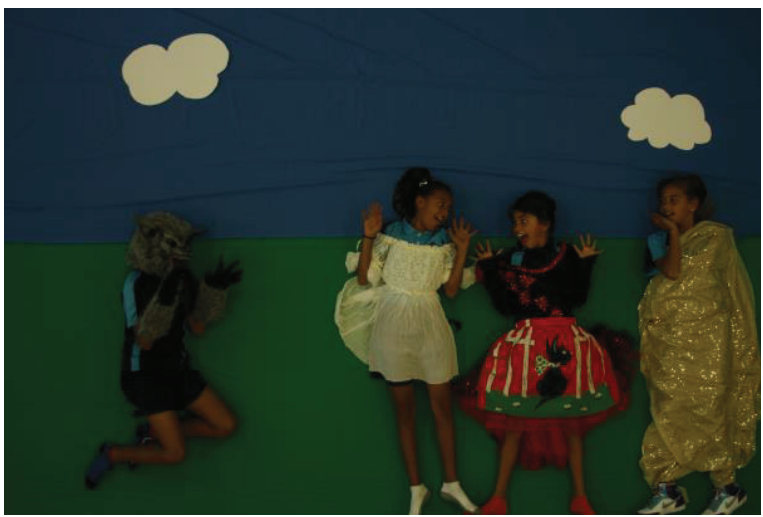

Figure 4: Michelle Williamson's "The Wolf"

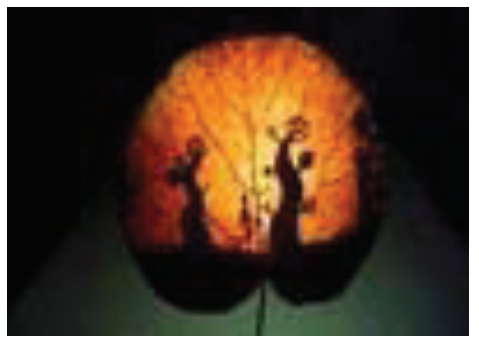

Figure 5: Michelle Williamson's "The Leaf"

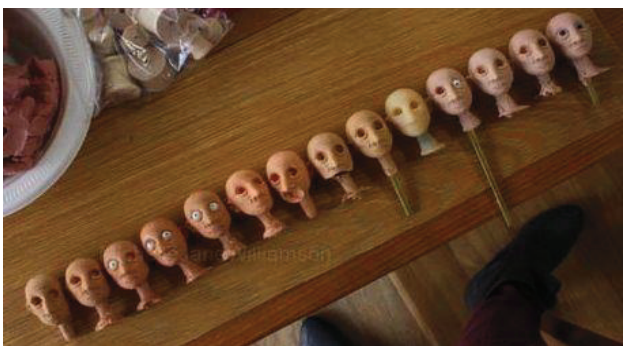

Figure 6: Michelle Williamson, production still 